\title{
PELE DE TILÁPIA: AVANÇO TECNOLÓGICO NO TRATAMENTO DE QUEIMADOS?
}

\section{ARTIGO DE REVISÃO}

CABRAL, Anna Julie Medeiros, LIMA, Camila Araújo Novais², CRUZ FILHO, Eduardo Franco Correia ${ }^{3}$, SOARES, Gabriel Lucena de Carvalho ${ }^{4}$, ESPÍNOLA, Paulo Francisco Lucena de Araújo ${ }^{5}$, ALVES, Fernanda Araújo ${ }^{6}$, CRUZ, Ana Suzy de Góis Melo ${ }^{7}$

CABRAL, Anna Julie Medeiros. Et al. Pele de tilápia: avanço tecnológico no tratamento de queimados?. Revista Científica Multidisciplinar Núcleo do Conhecimento. Ano. 06, Ed. 12, Vol. 05, pp. 50-64. Dezembro de 2021. ISSN: 24480959, Link de acesso: https://www.nucleodoconhecimento.com.br/saude/pele-detilapia, DOI: 10.32749/nucleodoconhecimento.com.br/saude/pele-de-tilapia

\section{RESUMO}

Introdução: A queimadura é uma das maiores agressões que o organismo pode sofrer. A conduta varia de acordo com o grau da queimadura, sendo desde o uso do clorexidine, sulfadiazina de prata, desbridamento do tecido necrótico, curativos biossintéticos e peles artificiais. Porém, esses dois últimos apresentam altos custos, desse modo, vários estudos surgiram com o objetivo de procurar opções mais viáveis, como o uso da pele da Tilápia do Nilo em queimados, devido a suas propriedades curativas. Dito isso, o presente artigo, tem como questão norteadora:

\footnotetext{
${ }^{1}$ Discente do curso de Medicina do Centro Universitário de João Pessoa - UNIPÊ, João Pessoa - PB. ORCID: 0000-0002-5212-5521.

${ }^{2}$ Discente do curso de Medicina do Centro Universitário de João Pessoa - UNIPÊ, João Pessoa - PB. ORCID: 0000-0003-4609-4260.

${ }^{3}$ Discente do curso de Medicina do Centro Universitário de João Pessoa - UNIPÊ, João Pessoa - PB. ORCID: 0000-0001-6684-2161.

${ }^{4}$ Discente do curso de Medicina do Centro Universitário de João Pessoa - UNIPÊ, João Pessoa - PB. ORCID: 0000-0002-0618-4037.

${ }^{5}$ Discente do curso de Medicina do Centro Universitário de João Pessoa - UNIPÊ, João Pessoa - PB. ORCID: 0000-0001-7964-2118.

${ }^{6}$ Orientadora. ORCID: 0000-0001-5235-5020.

${ }^{7}$ Orientador. ORCID: 0000-0002-0668-0540.
}

RC: 103232

Disponível em: https://www.nucleodoconhecimento.com.br/saude/pele-de-tilapia 
Seria esse novo método, de fato, um avanço tecnológico tão importante para o tratamento dos pacientes queimados quanto aparenta ser? Objetivo: Analisar o uso da pele da Tilápia do Nilo em pacientes com lesões por queimaduras, bem como comparar com outras técnicas preestabelecidas. Métodos: Trata-se de uma revisão bibliográfica do tipo integrativa, com abordagem qualitativa. Os dados foram coletados por meio das bases de dados PubMed e Biblioteca Virtual em Saúde (BVS), no período de 2015 a 2020. Resultados: Os artigos apontam um bom prognóstico à utilização da pele da Tilápia do Nilo em relação às demais opções vigentes para o tratamento de queimaduras, com vantagem expressiva na redução do número de curativos necessários, pela melhor adesão à ferida. Ademais, apresenta características microscópicas similares à pele humana, como a alta resistência à tração e extensão a quebra, com redução do tempo de reepitelização e intensidade da dor, bem como, redução dos custos do tratamento. Conclusão: Diante dos achados da literatura relatados na presente revisão, conclui-se que os estudos com a pele da Tilápia do Nilo demonstra ser uma modalidade revolucionária com benefícios no tratamento de pacientes com lesões superficiais e profundas da pele. Portanto, os pesquisadores concluíram, respondendo à pergunta norteadora, que o novo método constitui, sim, um importante avanço no âmbito do tratamento das queimaduras, por ter a sua empregabilidade confirmada, além de demonstrar vantagem sobre algumas das principais alternativas preexistentes.

Palavras-chave: Tilápia, Queimaduras, Curativos biológico.

\section{INTRODUÇÃO}

A velocidade e o estilo de vida impostos pela modernidade fazem com que a incidência do número de queimados aumente nos dias atuais. Muito além das lesões físicas, as queimaduras são também responsáveis por problemas econômicos associados com danos irreparáveis aos pacientes e suas famílias (HU et al., 2017). A queimadura é uma das maiores agressões que o organismo humano pode sofrer, sendo estimado que no Brasil, ocorram cerca de 1 milhão de acidentes com queimaduras anualmente, de acordo com Leontsinis et al. (2018), sejam estes uma 
simples insolação, queimaduras de primeiro grau, até a destruição total da pele (epiderme e derme) e dos tecidos adjacentes, como na queimadura de terceiro grau (ALVES et al., 2015).

Quando consideramos o tratamento dos queimados no Brasil, encaramos duas realidades: a da rede pública e privada. Nos centros de tratamento da rede pública, a conduta seguida em relação aos curativos nas lesões de segundo grau é o banho diário com clorexidine a $2 \%$ e o curativo é feito com o antimicrobiano tópico sulfadiazina de prata a $1 \%$ até a completa reparação da lesão; enquanto nas queimaduras de terceiro grau é realizado o desbridamento do tecido necrótico em várias etapas, sendo depois feito o curativo com sulfadiazina de prata a $1 \%$ até a preparação do leito da ferida para a enxertia. Em contrapartida, na rede privada, tomando em consideração as distintas condições financeiras de cada paciente, podem ser utilizados curativos biossintéticos e peles artificiais, opções importadas e de alto custo (ALVES et al., 2015).

Todavia, analisando a realidade vivenciada na Europa e nos Estados Unidos, o tratamento muitas vezes envolve o uso de peles homólogas (fazendo uso dos bancos de pele), heterólogas (de origem animal), curativos biossintéticos e derme artificial (ALVES et al., 2015). No Brasil, há ainda alguns enfrentamentos para se alcançar a mesma praticidade desses outros países. Culturalmente ainda se enfrenta uma grande resistência para a doação de pele, o que acaba por limitar a disponibilidade do tecido para atender a grande demanda. Além disso, tomando como referência o Ministério da Saúde, para que o Brasil possa suprir a necessidade de pele homóloga para uso em lesões por queimaduras, seria necessário ter 13 bancos de pele distribuídos pelo território nacional, entretanto existem apenas cinco (São Paulo, Curitiba, Rio de Janeiro, Porto Alegre e Recife - que está desativado). Somando-se a essas limitações, o Brasil nunca teve uma pele animal registrada na Agência Nacional de Vigilância Sanitária (ANVISA) e disponibilizada pelo Sistema Único de Saúde (SUS), o que também acaba por restringir o uso de pele heteróloga em pacientes queimados (LEONTSINIS et al., 2018). 
Desse modo, vários estudos surgiram com o objetivo de procurar curativos para serem utilizados em pacientes queimados. Esses curativos têm por intuito reduzir os efeitos da contaminação nas lesões, favorecer o processo cicatricial e oferecer melhores resultados estéticos. Tendo, de maneira ideal, boa flexibilidade e aderência ao leito, resistência ao estiramento, fácil manipulação, capacidade de suprimir a dor, baixo custo e fácil obtenção, bem como previne as perdas hidroeletrolíticas, a contaminação bacteriana, favorece a epitelização das queimaduras e propicia a formação do adequado tecido de granulação. Uma das opções é a busca por substitutos temporários da pele e curativos de materiais sintéticos ou biossintéticos, pois reduzem a frequência de troca do curativo, contudo, os altos custos e sua ineficácia para queimaduras profundas estimularam a busca por materiais biológicos como alternativas viáveis (COSTA et al., 2019; MARCELO e BRANDT, 2019).

Nesse âmbito, em 2011, o médico cirurgião plástico pernambucano Marcelo Borges, após ver uma matéria no Jornal do Commercio de Pernambuco falando sobre o uso da pele da espécie Tilápia do Nilo (Oreochromis niloticus) no artesanato, um dos peixes mais cultivados no Brasil, surgiu primeiro com a ideia de utilizar esta pele no tratamento de queimaduras. Mas só em 2014, compartilhou a ideia com o cirurgião plástico cearense Edmar Maciel, dando então início aos estudos sobre a utilização da pele da Tilápia do Nilo em queimados. Ainda foram integrados para compor a coordenação do trabalho o pesquisador Odorico Moraes, diretor presidente do Núcleo de Pesquisa e Desenvolvimento de Medicamentos (NPDM), na Universidade Federal do Ceará (UFC), e o cirurgião plástico de Goiás Nelson Piccolo (LIMA JUNIOR et al., 2017).

Conforme narrado por Lima Junior (2017), a pele da Tilápia do Nilo demonstra uma epiderme revestida por um epitélio pavimentoso estratificado, seguido de extensas camadas de colágeno. Graças a sua característica de orientar e definir a maioria dos tecidos, configura-se como um grande componente dos biomateriais, além de possibilitar biodegradabilidade e biocompatibilidade, que favorecem sua aplicação (LIMA JUNIOR, 2017; LIMA JUNIOR et al., 2019b, 2020b). 
Dito isso, a questão norteadora é: "Seria esse novo método, de fato, um avanço tecnológico tão importante para o tratamento dos pacientes queimados quanto aparenta ser?" Objetiva-se, então, por meio desse estudo, analisar se a pele de Tilápia do Nilo é uma alternativa viável para ser utilizada em pacientes com lesões por queimadura, bem como comparar com outras técnicas já utilizadas, verificando as vantagens da adoção desse novo método.

De maneira mais específica, esse estudo tem como objetivo evidenciar a boa adesão do curativo de pele de tilápia no tratamento de queimaduras, correlacionando as propriedades físico-químicas da tilápia com os benefícios do curativo e expondo a não inferioridade dos curativos de pele de tilápia em relação às demais soluções existentes no mercado. Além de instigar a realização de maiores pesquisas científicas para obtenção de resultados mais robustos acerca do tema.

\section{METODOLOGIA}

Refere-se a uma revisão bibliográfica do tipo integrativa, com abordagem qualitativa, com intuito descritivo de estudos nacionais e internacionais. Ademais, apresenta natureza aplicada, com o uso de procedimento bibliográfico para análise dos respectivos dados coletados relativos à utilização da pele da tilápia nos pacientes queimados.

O presente estudo foi realizado através da busca de artigos por meio do acesso das bases de dados PubMed e a Biblioteca Virtual de Saúde (BVS). A princípio foi realizada a coleta dos descritores pertinentes aos âmbitos do tema selecionado, sendo vocabulário dos Descritores em Ciências da Saúde (DeCS). Os termos escolhidos foram "Tilápia", "Queimaduras" e "Curativos Biológicos" nos idiomas: português, inglês e espanhol. Tais descritores foram associados aos operadores booleanos "OR" e "AND" elaborando a seguinte fórmula de pesquisa: "(Tilápia OR Tilapia OR Tilapia) AND (Queimaduras OR Burns OR Quemaduras) AND (Curativos Biológicos OR Biological Dressings OR Apósitos Biológicos)". 
Com isso, aplicando a fundamentação da fórmula supracitada, foram encontrados um total de 31 artigos nas bases de dados selecionadas, sendo 14 artigos da PubMed e 17 disponíveis na BVS. Os critérios de inclusão foram: artigos disponíveis na íntegra, que retratassem a temática referente à revisão integrativa e artigos publicados e indexados nas bases de dados publicadas nos anos 2015, 2016, 2017, 2018, 2019, 2020 e 2021, que apresentassem o idioma em inglês, português e espanhol. Ademais, os artigos que estavam duplicados, não apresentavam conteúdo na íntegra e que não atendiam aos objetivos da pesquisa foram excluídos da revisão integrativa.

A revisão bibliográfica integrativa não tem caráter prático, portanto, dispensa a necessidade de submissão ao Comitê de Ética em Pesquisas (CEP). Nessa perspectiva, foi elaborada uma tabela apresentando as principais informações das bibliografias utilizadas, apresentando os dados referentes ao título, autores, ano de publicação, país e os principais resultados de cada uma.

\section{RESULTADOS}

Quadro 1: Utilização de pele da tilápia em queimados: embasamento teórico e implicações práticas.

\begin{tabular}{|l|l|l|l|}
\hline & Título & $\begin{array}{l}\text { Autores, } \\
\text { ano de } \\
\text { publicação } \\
\text { e país }\end{array}$ & Principais resultados \\
\hline $\mathbf{A R T I G O}$ & $\begin{array}{l}\text { Uso da pele de tilápia } \\
\text { (Oreochromis niloticus), }\end{array}$ & Lima Júnior & et al., 2017, \\
\hline $\mathbf{1}$ & $\begin{array}{l}\text { Omo estudo mostrou que a pele } \\
\text { da tilápia possui uma } \\
\text { oclusivo, no tratamento de } \\
\text { queimaduras }\end{array}$ & Brasil & $\begin{array}{l}\text { considerável aderência às } \\
\text { feridas por queimaduras nos } \\
\text { ratos do teste, com resultado }\end{array}$ \\
\hline
\end{tabular}




\begin{tabular}{|c|c|c|c|}
\hline & & & $\begin{array}{l}\text { positivo ao decorrer da } \\
\text { cicatrização, sem mutações } \\
\text { significativas nos âmbitos } \\
\text { bioquímicos e hematológicos } \\
\text { da função hepática e renal, } \\
\text { constituindo-se como uma } \\
\text { possibilidade de curativo } \\
\text { biológico. }\end{array}$ \\
\hline $\begin{array}{l}\text { ARTIGO } \\
2\end{array}$ & $\begin{array}{l}\text { Xenoenxerto (pele da } \\
\text { Tilápia-do-Nilo) } \\
\text { hidrofibra com prata no } \\
\text { tratamento } \\
\text { queimaduras de II grau } \\
\text { em adultos }\end{array}$ & $\begin{array}{l}\text { De Miranda } \\
\text { e Brandt, } \\
2019, \\
\text { Brasil }\end{array}$ & $\begin{array}{l}\text { A pesquisa evidenciou que a } \\
\text { Tilápia do Nilo apresenta } \\
\text { eficácia na função de } \\
\text { curativo biológico oclusivo no } \\
\text { tratamento de queimaduras } \\
\text { de } 2^{\circ} \text { grau em adultos, com } \\
\text { médias similares quanto ao } \\
\text { tempo de dratamento, } \\
\text { referência de dor } \\
\text { necessidade de substituição, } \\
\text { quanto ao manejo dos } \\
\text { pacientes com Aquacel } A G \AA .\end{array}$ \\
\hline $\begin{array}{l}\text { ARTIGO } \\
3\end{array}$ & $\begin{array}{l}\text { Avaliação microscópica, } \\
\text { estudo histoquímico e } \\
\text { análise de propriedades } \\
\text { tensiométricas da pele de } \\
\text { tilápia do Nilo }\end{array}$ & $\begin{array}{l}\text { Alves et al., } \\
\text { 2015, Brasil }\end{array}$ & $\begin{array}{l}\text { A pele da tilápia apresenta } \\
\text { feixes de fibras de colágeno } \\
\text { denso, predominantemente } \\
\text { do tipo } 1 \text {, apresentando } \\
\text { características microscópicas } \\
\text { similares às da pele humana, } \\
\text { bem como alta resistência à } \\
\text { tração e extensão a quebra, } \\
\text { tornando-a promissora como } \\
\text { biomaterial na medicina } \\
\text { regenerativa. }\end{array}$ \\
\hline
\end{tabular}

RC: 103232

Disponível em: https://www.nucleodoconhecimento.com.br/saude/pele-de-tilapia 


\begin{tabular}{|c|c|c|c|}
\hline ARTIGO & $\begin{array}{l}\text { Innovative Burn Treatment } \\
\text { Using Tilapia Skin as a } \\
\text { Xenograft: A Phase II } \\
\text { Randomized Controlled } \\
\text { trial }\end{array}$ & $\begin{array}{l}\text { Lima Júnior } \\
\text { et al., 2020, } \\
\text { Brasil }\end{array}$ & $\begin{array}{l}\text { O ensaio clínico } \\
\text { randomizado utilizou uma } \\
\text { amostra de } 62 \text { participantes } \\
\text { e demonstrou que houve } \\
\text { redução quanto: ao tempo de } \\
\text { reepitelização, intensidade } \\
\text { da dor, a quantidade de } \\
\text { anestesicos/analgesicos e a } \\
\text { necessidade de troca de } \\
\text { curativos em comparação ao } \\
\text { grupo controle, portanto, a } \\
\text { pele da tilápia apresentou } \\
\text { benefícios. }\end{array}$ \\
\hline $\begin{array}{l}\text { ARTIGO } \\
5\end{array}$ & $\begin{array}{l}\text { Tratamento } r \\
\text { queimaduras de segundo } \\
\text { grau profundo em } \\
\text { abdômen, coxas e } \\
\text { genitália: uso da pele de } \\
\text { tilápia como um } \\
\text { xenoenxerto }\end{array}$ & $\begin{array}{l}\text { Lima Júnior } \\
\text { et al., 2020, } \\
\text { Brasil }\end{array}$ & $\begin{array}{l}\text { O relato de caso contribuiu } \\
\text { para reduzir as limitações } \\
\text { relacionadas ao acesso de } \\
\text { áreas anatômicas mais } \\
\text { inacessíveis, para o uso, } \\
\text { apresentando bons } \\
\text { resultados na aplicação na } \\
\text { genitália e região inguinal. É } \\
\text { uma opção de elevada } \\
\text { disponibilidade e simples } \\
\text { aplicação. }\end{array}$ \\
\hline ARTIGC & $\begin{array}{l}\text { Marine Collagen Peptides } \\
\text { from the Skin of Nile } \\
\text { Tilapia (Oreochromis } \\
\text { niloticus): Characterization } \\
\text { and Wound Healing } \\
\text { Evaluation }\end{array}$ & $\begin{array}{l}\text { Zhang } \mathrm{Hu} \\
\text { et al., 2017, } \\
\text { China }\end{array}$ & $\begin{array}{l}\text { O ensaio de raspagem in } \\
\text { vitro e in vivo revelou } \\
\text { consequências significativas } \\
\text { no fechamento de raspagem } \\
\text { com a pele da tilápia, com } \\
\text { evolução no processo da } \\
\text { cicatrização por escaldadura }\end{array}$ \\
\hline
\end{tabular}




\begin{tabular}{|c|c|c|c|}
\hline & & & $\begin{array}{l}\text { de espessura parcial } \\
\text { profunda nos coelhos } \\
\text { testados, apresentando-se } \\
\text { como um tratamento } \\
\text { promissor. }\end{array}$ \\
\hline $\begin{array}{l}\text { ARTIGO } \\
7\end{array}$ & $\begin{array}{l}\text { A Randomized } \\
\text { Comparison Study of } \\
\text { Lyophilized Nile Tilapia } \\
\text { Skin and Silver- } \\
\text { Impregnated Sodium } \\
\text { Carboxymethylcellulose } \\
\text { for the Treatment of } \\
\text { Superficial Partial- } \\
\text { Thickness Burns }\end{array}$ & $\begin{array}{l}\text { Lima } \\
\text { Júnior, et } \\
\text { al., 2020, } \\
\text { Brasil }\end{array}$ & $\begin{array}{l}\text { Esse estudo piloto } \\
\text { demonstrou que não há } \\
\text { inferioridade quanto a pele } \\
\text { de tilápia liofilizada como } \\
\text { opção terapêutica nas } \\
\text { queimaduras, } \\
\text { comparação com o curativo } \\
\text { de carboximetilcelulose } \\
\text { sódica impregnada com } \\
\text { prata, com eficácia } \\
\text { segurança, possibilitando o } \\
\text { desenvolvimento de ensaios } \\
\text { clínicos randomizados mais } \\
\text { complexos futuramente. }\end{array}$ \\
\hline $\begin{array}{l}\text { ARTIGO } \\
8\end{array}$ & $\begin{array}{l}\text { Elaboração de um } \\
\text { protocolo para } \\
\text { implementação } \\
\text { funcionamento do primeiro } \\
\text { banco de pele animal do } \\
\text { Brasil: Relato de } \\
\text { experiência }\end{array}$ & $\begin{array}{l}\text { Leontsinis } \\
\text { et al., 2018, } \\
\text { Brasil }\end{array}$ & $\begin{array}{l}\text { O artigo revelou a } \\
\text { importância da elaboração e } \\
\text { implementação de protocolos } \\
\text { para o primeiro Banco de } \\
\text { pele animal aquática do } \\
\text { mundo, reforçando a } \\
\text { necessidade } \\
\text { estabelecimento da } \\
\text { uniformização do sistema. }\end{array}$ \\
\hline $\begin{array}{l}\text { ARTIGO } \\
9\end{array}$ & $\begin{array}{l}\text { Use of Tilapia Skin as a } \\
\text { Xenograft for Pediatric } \\
\text { Burn Treatment: A Case }\end{array}$ & $\begin{array}{l}\text { Costa et al., } \\
2019, \\
\text { Estados }\end{array}$ & $\begin{array}{l}\text { O xenoenxerto de pele de } \\
\text { tilápia no relato de caso de } \\
\text { uma criança de } 3 \text { anos vítima }\end{array}$ \\
\hline
\end{tabular}




\begin{tabular}{|c|c|c|c|}
\hline & Report & Unidos & $\begin{array}{l}\text { de queimaduras demonstrou } \\
\text { resultados positivos com } \\
\text { significativo impacto tanto } \\
\text { social, quanto financeiro para } \\
\text { o sistema de saúde. }\end{array}$ \\
\hline $\begin{array}{l}\text { ARTIGO } \\
10\end{array}$ & $\begin{array}{l}\text { Innovative treatment using } \\
\text { tilapia skin as a xenograft } \\
\text { for partial thickness burns } \\
\text { after a gunpowder } \\
\text { explosion }\end{array}$ & $\begin{array}{l}\text { Lima Júnior } \\
\text { et al., 2019, } \\
\text { Inglaterra }\end{array}$ & $\begin{array}{l}\text { O relato de caso retrata um } \\
\text { paciente do sexo masculino, } \\
\text { de } 23 \text { anos, com } \\
\text { queimaduras superficiais e } \\
\text { profundas no membro } \\
\text { superior direito e esquerdo, } \\
\text { respectivamente. Com o uso } \\
\text { da pele da tilápia, a } \\
\text { reepitelização foi realizada } \\
\text { em um tempo curto, sem } \\
\text { efeitos colaterais } \mathrm{e} \\
\text { necessidade de troca de } \\
\text { curativo. }\end{array}$ \\
\hline $\begin{array}{l}\text { ARTIGO } \\
11\end{array}$ & $\begin{array}{l}\text { Pediatric Burn Treatment } \\
\text { Using Tilapia Skin as a } \\
\text { Xenograft for Superficial } \\
\text { Partial-Thickness } \\
\text { Wounds: A Pilot Study }\end{array}$ & $\begin{array}{l}\text { Lima } \\
\text { Júnior, } \\
2020, \\
\text { Inglaterra }\end{array}$ & $\begin{array}{l}\text { O uso da pele da tilápia foi } \\
\text { utilizado como um recurso } \\
\text { extra juntamente com a } \\
\text { sulfadiazina de prata. O } \\
\text { estudo revelou que além de } \\
\text { trazer benefícios para os } \\
\text { pacientes, diminuiu os custos } \\
\text { do tratamento, bem como, } \\
\text { para os profissionais de } \\
\text { saúde, como redução da } \\
\text { carga de trabalho. }\end{array}$ \\
\hline $\begin{array}{l}\text { ARTIGO } \\
12\end{array}$ & $\begin{array}{l}\text { Comprehensive } \\
\text { Assessment of Nile Tilapia }\end{array}$ & Ge et al., & $\begin{array}{l}\text { O curativo de hidrogel de } \\
\text { colágeno, apresentou a }\end{array}$ \\
\hline
\end{tabular}




\begin{tabular}{|c|c|c|c|}
\hline & $\begin{array}{lrr}\text { Skin } & \text { (Oreochromis } \\
\text { niloticus) } & \text { Collagen } \\
\text { Hydrogels } & \text { for } & \text { Wound } \\
\text { Dressings } & & \end{array}$ & 2020, China & $\begin{array}{l}\text { promoção da formação de } \\
\text { camadas epidérmicas e a } \\
\text { maturação dos apêndices da } \\
\text { pele, demonstrando ser um } \\
\text { excelente curativo novo com } \\
\text { eficácia no manejo de } \\
\text { queimaduras profundas. }\end{array}$ \\
\hline $\begin{array}{l}\text { ARTIGO } \\
13\end{array}$ & $\begin{array}{l}\text { Tecnologias inovadoras: } \\
\text { uso da pele da tilápia do } \\
\text { Nilo no tratamento de } \\
\text { queimaduras e feridas }\end{array}$ & $\begin{array}{l}\text { Lima } \\
\text { Júnior, } \\
\text { 2017, Brasil }\end{array}$ & $\begin{array}{l}\text { A pele de tilápia em } \\
\text { queimados é uma patente } \\
\text { brasileira, sendo o objetivo } \\
\text { das pesquisas o registro da } \\
\text { pele na Agência Nacional de } \\
\text { Vigilância Sanitária (ANVISA) } \\
\text { e disponibilizada pelo } \\
\text { Sistema Único de Saúde } \\
\text { (SUS). }\end{array}$ \\
\hline $\begin{array}{l}\text { ARTIGO } \\
14\end{array}$ & $\begin{array}{l}\text { Chitosan hydrogel in } \\
\text { combination with marine } \\
\text { peptides from tilapia for } \\
\text { burns healing }\end{array}$ & $\begin{array}{l}\text { Ouyang et } \\
\text { al., 2018, } \\
\text { China }\end{array}$ & $\begin{array}{l}\text { Os peptídeos marinhos } \\
\text { extraídos da tilápia } \\
\text { evidenciaram uma } \\
\text { composição semelhante a do } \\
\text { colágeno, além de atividade } \\
\text { antibacteriana significativa. } \\
\text { Apresenta alta eficiência de } \\
\text { cura e habilidades de } \\
\text { migração e proliferação } \\
\text { celular em comparação ao } \\
\text { grupo controle e outras } \\
\text { pomadas disponíveis na } \\
\text { indústria farmacêutica. }\end{array}$ \\
\hline
\end{tabular}

Fonte: Desenvolvido pelo autor (2021) 
A revisão incluiu 14 artigos, dentre os quais, dois (14,3\%) discorreram sobre os resultados com utilização de testes animais, 14,3\% sobre uma análise comparativa entre os tratamentos tradicionais e o uso da pele da tilápia, e 21,4\% acerca dos mecanismos da composição e propriedades em relação a pele humana. $\mathrm{O}$ uso de ensaio randomizado representou $7,1 \%$ dos artigos, $28,6 \%$ apresentaram os resultados em relatos de caso e $14,3 \%$ explanaram o desenvolvimento da técnica até a sua importância nos bancos de pele na atualidade.

O estudo realizado no Centro de Tratamento de Queimados do Instituto Dr. José Frota, Hospital público de Fortaleza, Ceará, Brasil, selecionou 62 pacientes hospitalizados entre outubro de 2016 a setembro de 2017, vítimas de queimaduras. As variantes avaliadas foram: o número de vezes que houve troca do curativo oclusivo e de dias para cicatrização de feridas, uso de analgésicos ou anestésicos, sensibilidade dolorosa, melhora da queimadura na retirada do curativo. $O$ estudo analisou os dados e dividiu os participantes, a partir do: sexo, idade, agentes responsáveis pelo acidente, superficie corporal e segmentos queimados, e para isso, dividiram em três classificações, A - pacientes ambulatóriais com espessura parcial superficial queimaduras menor que $10 \%$, B - pacientes internados com a mesma de 10 a $20 \%$, C - pacientes internados com queimaduras profundas de espessura parcial de 5 a $15 \%$, e cada uma dessa classificação foi dividida aleatoriamente em dois grupos de tratamento: $48,4 \%(n=30)$ Grupo de Teste usando a pele da tilápia como xenoenxerto e $51,6 \%$ ( $n=32)$ Grupo Controle: convencional com creme de sulfadiazina. O principal mecanismo de queimaduras do Grupo Teste (classificações $\mathrm{A}, \mathrm{B}$ e $\mathrm{C}$ utilizando a pele de tilápia como tratamento) foi por líquidos quentes $56,25 \%(n=18)$. A avaliação da intensidade de dor foi menor no grupo teste em comparação com o grupo controle. O número de curativos necessários ao longo do tratamento, no grupo teste foi menor, apresentando $2.08 \pm 0.28$ (A), $2.33 \pm 0.71$ (B), $6.10 \pm 2.02(C)$, enquanto no grupo controle $5.80 \pm 0.42(A), 11.00 \pm 0.47(B), 20.20 \pm$ 1.69 (C) levando em consideração o valor de $\mathrm{P}$ como 0.0001 . Em relação ao número de dias para reepitelização completa, o grupo teste apresentou os melhores resultados, possuindo: $9.77 \pm 0.83(A), 10.56 \pm 1.13$ (B), $18.10 \pm 0.99$ (C), enquanto o 
grupo controle: $11.20 \pm 0.63(\mathrm{~A}), 11.70 \pm 0.67$ (B), $21.30 \pm 1.42$ ( , considerando aproximadamente $\mathrm{P}<0.0147$ (LIMA JUNIOR et al., 2020a)

Outro estudo feito no Centro de Tratamento de Queimados em Fortaleza, Ceará, Brasil, selecionou 30 crianças, entre 2 - 12 anos, hospitalizadas entre maio de 2017 e março de 2018. As variáveis utilizadas foram: os dias totais para completa cicatrização da queimadura e o número de curativos utilizados. Os pacientes foram divididos em dois grupos, em que $50 \%$ foram alocadas para o grupo teste da pele de tilápia e o restante para o grupo da sulfadiazina de prata. O número médio de dias para completar a reepitelização foi de $10,47 \pm 0,74$ no grupo da sulfadiazina de prata e 10,07 $\pm 0,46$ no grupo da pele da tilápia. A diferença entre os dois grupos não foi estatisticamente significativa $(P=0,0868)$. $O$ número de curativos sob anestesia realizados em pacientes tratados com pele de tilápia foi menor que os realizados nos voluntários tratados com sulfadiazina de prata. Uma diferença estatisticamente significativa também foi encontrada para o número de curativos sem anestésicos. Por fim, o número total de curativos foi significativamente reduzido no grupo pele de tilápia $(3,00 \pm 0,76)$ quando comparado ao grupo sulfadiazina de prata $(9,27 \pm 1,39)$ (LIMA JUNIOR et al., 2019a).

\section{DISCUSSÃO}

O estudo das propriedades da pele da tilápia é um bom ponto de partida para entender o seu potencial de utilização em queimaduras. Para isso, vale analisar primeiramente os achados de Hu et al. (2017) que estudou o uso de um concentrado de polipeptídeos de colágeno extraído da pele da tilápia, com enfoque no seu potencial curativo. Os ensaios in vitro utilizando células humanas preparadas demonstraram que a adição de $50.0 \mu \mathrm{g} / \mathrm{mL}$ do concentrado ao tecido lesado trouxe resultados estatisticamente significativos em relação à velocidade de regeneração e reepitelização do tecido. Já os estudos in vivo do mesmo autor mostraram resultados promissores quanto à cicatrização por escaldadura de espessura parcial profunda nos coelhos testados. Os achados foram semelhantes aos obtidos com o 
curativo de hidrogel de colágeno, estudado por Ge et al. (2020), para queimaduras profundas.

Ademais, outros estudos foram feitos para avaliar as propriedades da pele do animal. Segundo Alves et al. (2015), a pele da tilápia apresenta feixes de fibras de colágeno denso, predominantemente do tipo 1, com características microscópicas similares às da pele humana, bem como alta resistência à tração e extensão, tornando-a promissora como biomaterial na medicina regenerativa. O estudo de Ouyang et al. (2018) corrobora com esses resultados, bem como os de $\mathrm{Hu}$ et al. (2017), que ainda aborda a atividade antibacteriana do material e compara a sua eficiência de cura com outras soluções disponíveis no mercado, obtendo uma alta eficiência, além de propiciar migração e proliferação celular.

Validado esse potencial curativo da pele da tilápia, é preciso entender a usabilidade desse material na forma de curativos biológicos. Segundo o estudo de Lima Junior (2017), a pele da tilápia possui uma considerável aderência às feridas por queimaduras nos ratos do teste, com resultado positivo ao decorrer da cicatrização, sem mutações significativas nos âmbitos bioquímicos e hematológicos da função hepática e renal, constituindo-se como uma possibilidade positiva como curativo biológico. Corroborando com esses resultados, o ensaio clínico randomizado de Lima Junior et al. (2020c) mostrou boa aderência em pacientes, bem como outras vantagens em relação a outros curativos, como o Aquacel $\mathrm{Ag}{ }^{\circledR}$, que será discutido posteriormente.

Dito isso, cabe comparar a pele da tilápia com as demais soluções existentes em se tratando de queimaduras. Lima Junior et al. (2020c) e Marcelo e Brandt (2019) promoveram estudos que demonstram não haver inferioridade quanto à pele de tilápia liofilizada, em comparação com o curativo de carboximetilcelulose sódica impregnada com prata, o Aquacel $\mathrm{Ag}{ }^{\circledR}$. O estudo de Lima Junior et al. (2020c) enfatiza que o uso da pele de tilápia oferece uma melhora subjetiva na quantidade de dor relatada e número de curativos necessários, reduzindo, dessa forma, o custo do tratamento e a carga de trabalho da equipe. Logo, a pele de tilápia mostra-se uma boa opção para o tratamento de queimaduras. 


\section{CONCLUSÃO}

Diante dos achados da literatura relatados na presente revisão, conclui-se que os estudos com a pele da Tilápia do Nilo, peixe de água doce, realizados pelos pesquisadores da Universidade Federal do Ceará, que foram, desde 2016, os pioneiros a patentear o método. Outrossim, vem sendo uma modalidade revolucionária com inúmeros benefícios no tratamento de pacientes com lesões superficiais e profundas da pele expandindo-se para diversas áreas da medicina, testadas na medicina veterinária, dentro e fora do país (LIMA JUNIOR, 2017).

Com base nos registros das pesquisas, reforça-se os benefícios do uso da Pele da Tilápia no tratamento das queimaduras, tendo em vista que oferece redução da dor do paciente em virtude ao período maior aderido à pele do paciente. Além do reduzido poder de infecção e contaminação, elevada resistência devido a grande quantidade de colágeno presente no couro do peixe, resultando em boa estética e baixo custo, comparado às demais formas de tratamento.

Portanto, os pesquisadores chegaram à conclusão, respondendo à pergunta norteadora, de que o novo método constitui, sim, um importante avanço no âmbito do tratamento das queimaduras, por ter a sua empregabilidade confirmada, além de demonstrar vantagem sobre algumas das principais alternativas preexistentes.

\section{REFERÊNCIAS}

ALVES, Ana; VERDE, Maria; FERREIRA FILHO, Antônio; SILVA, Paulo; FEITOSA, Victor; LIMA JUNIOR, Edmar; MIRANDA, Marcelo; MORAES FILHO, Manoel. Avaliação microscópica, estudo histoquímico e análise de propriedades tensiométricas da pele de tilápia do Nilo. Revista Brasileira de Queimaduras, v. 14, n. 3, p. 203-210, 2015.

COSTA, Bruno; LIMA JÚNIOR, Edmar; MORAES FILHO, Manoel; FECHINE, Francisco; MORAES, Maria; SILVA JUNIOR, Francisco; SOARES, Maria; ROCHA, 
Marina. Use of Tilapia Skin as a Xenograft for Pediatric Burn Treatment: A Case Report. Journal of Burn Care \& Research, v. 40, n. 5, p. 714-717, 2019.

GE, Baosheng; WANG, Haonan; LI, Jie; LIU, Hengheng; YIN, Yonghao; ZHANG, Naili; QIN, Song. Comprehensive Assessment of Nile Tilapia Skin (Oreochromis niloticus) Collagen Hydrogels for Wound Dressings. Marine Drugs, v. 18, n. 4, p. $178,2020$.

HU, Zhang; YANG, Ping; ZHOU, Chunxia; LI, Sidong; HONG, Pengzhi. Marine Collagen Peptides from the Skin of Nile Tilapia (Oreochromis niloticus): Characterization and Wound Healing Evaluation. Marine Drugs, v. 15, n. 4, p. 102, 2017.

LEONTSINIS, Cybele; LIMA JUNIOR, Edmar; MORAIS FILHO, Manoel; BRITO, Maria; ROCHA, Marina; NASCIMENTO, Maria; SILVA JUNIOR, Francisco; MIRANDA, Marcelo. Elaboração de um protocolo para implementação e funcionamento do primeiro banco de pele animal do Brasil: Relato de experiência. Revista Brasileira de Queimaduras, v. 17, n. 1, p. 66-71, 2018.

LIMA JUNIOR, Edmar; PICOLLO, Nelson; MIRANDA, Marcelo; RIBEIRO, Wesley; ALVES, Ana; FERREIRA, Guilherme; PARENTE, Ezequiel, MORAES FILHO, Manoel. Uso da pele de tilápia (Oreochromis niloticus), como curativo biológico oclusivo, no tratamento de queimaduras. Revista Brasileira de Queimaduras, v. 16, n. 1 , p. 10-17, 2017.

LIMA JÚNIOR, Edmar. Tecnologias inovadoras: uso da pele da tilápia do Nilo no tratamento de queimaduras e feridas. Revista Brasileira de Queimaduras, v. 16, n. 1, p. 1-2, 2017.

LIMA JÚNIOR, Edmar; MORAES FILHO, Manoel; FORTE, Antônio; COSTA, Bruno; ; FECHINE, Francisco; ALVES, Ana; MORAES, Maria; ROCHA, Marina; SILVA JUNIOR, Francisco; SOARES, Maria; BEZERRA, Alane; MARTINS, Camila; MATHOR, Mônica. Pediatric Burn Treatment Using Tilapia Skin as a Xenograft for 
Superficial Partial-Thickness Wounds: A Pilot Study. Journal of Burn Care \& Research, 2019a.

LIMA JUNIOR, Edmar; MORAES FILHO, Manoel; COSTA, Bruno Almeida; FECHINE, Francisco; MORAES, Maria; SILVA JUNIOR, Francisco; SOARES, MARIA; ROCHA, MARINA, LEONTSINIS, Cybele. Innovative treatment using tilapia skin as a xenograft for partial thickness burns after a gunpowder explosion. Journal of Surgical Case Reports, v. 2019, n. 6, $2019 \mathrm{~b}$.

LIMA JÚNIOR, Edmar; MORAES FILHO, Manoel; COSTA, Bruno; ROHLEDER, Andréa; ROCHA, Marina; FECHINE, Francisco; FORTE, Antonio. ALVES, Ana, SILVA JUNIOR, Francisco; MARINS, Camila; MATHOR, Mônica; MORAES, Maria. Innovative Burn Treatment Using Tilapia Skin as a Xenograft: A Phase II Randomized Controlled Trial. Journal of Burn Care \& Research, v. 41, n. 3, p. 585592, 2020a.

LIMA JUNIOR, Edmar; MORAES, Manoel Odorico; COSTA, Bruno Almeida; UCHÔA, Alex; MARTINS, Camila; MORAES, Maria; ROCHA, Marina; FECHINE, Rodrigo. Treatment of deep second-degree burns on the abdomen, thighs, and genitalia: use of tilapia skin as a xenograft. Revista Brasileira de Cirurgia Plástica (RBCP) - Brazilian Journal of Plastic Sugery, v. 35, n. 2, p. 243-248, 2020b.

LIMA JÚNIOR, Edmar; MORAES FILHO, Manoel ; COSTA, Bruno Almeida; FECHINE, Francisco; ROCHA, Marina; VALE, Mariana; DIÓGENES, Ana; UCHÔA, Alex; SILVA JUNIOR, Francisco; MARTINS, Camila; BANDEIRA, Tereza; RODRIGUES, Felipe; PAIER, Carlos; MORAES, Maria. A Randomized Comparison Study of Lyophilized Nile Tilapia Skin and Silver-Impregnated Sodium Carboxymethylcellulose for the Treatment of Superficial Partial-Thickness Burns. Journal of Burn Care \& Research, v. 42, n. 1, p. 41-48, 2020 c. 
DE MIRANDA, Marcelo José Borges; BRANDT, Carlos Teixeira. Xenoenxerto (pele da Tilápia-do-Nilo) e hidrofibra com prata no tratamento das queimaduras de II grau em adultos. Rev. bras. cir. plást, p. 79-85, 2019.

OUYANG, Qian-Qian; HU, Zhang; LIN, Zhen-Peng; QUAN, Wei-Yan; DENG, YiFeng; LI, Si-Dong; LI, Pu-Wang, CHEN, Yu. Chitosan hydrogel in combination with marine peptides from tilapia for burns healing. International Journal of Biological Macromolecules, v. 112, p. 1191-1198, 2018.

Enviado: Julho, 2021.

Aprovado: Dezembro, 2021. 